\title{
PREFACE for the Special 50th Volume of Heterocycles
}

From today's perspective, it is almost incomprehensible that there was a time, not too many decades ago, when discussions (usually very brief ones) of heterocyclic chemistry were relegated to the back pages of textbooks, and the area was generally considered to be an over-specialized, narrow, relatively unchallenging branch of organic chemistry. Today, papers dealing with one or another aspect of heterocyclic chemistry constitute some $75-80 \%$ of all publications in organic chemistry. Heterocycles make up a significant percentage of all known medicinal and agricultural agents, and are widely distributed in nature as vitamins, hormones, constituents of DNA and RNA, essential amino acids, carbohydrates, alkaloids and antibiotics. Numbers of known heterocyclic compounds, with heteroatoms well beyond $N, S$, and $O$, are exploding exponentially with the advent of combinatorial chemistry. Heterocycles are demonstrating extraordinary versatility and utility in the field of organic synthesis as chiral auxiliaries, latent functionalities, protecting groups, chelating agents and synthetic scaffolds. Heterocycles, indeed, are an integral part of the very fabric of organic and biological chemistry.

The pioneering periodical HETEROCYCLES is playing a major role in contemporary chemical literature as a highly respected vehicle for publication of original papers, communications and reviews in the field of heterocyclic chemistry, A joumal devoted to what might appear to be a single discipline within in the fieid of chemistry has both potential advantages as well as drawbacks. HETEROCYCLES possesses the former, and avoids the latter, through its unremitting emphasis on quality, significance and breadth. The field of heterocyclic chemistry, impinging as it does on almost every facet of organic and medicinal chemistry - structure, mechanism, synthesis, properties (both chemical and biological), and utility - was in real need of a first-rate journal that provided chemists with access to and perspectives on the best of current research in this extremely broad field. This is the 50th volume of this flagship periodical, and chemists the world over can be grateful for the contributions it has and we trust will continue to make to chemical progress.

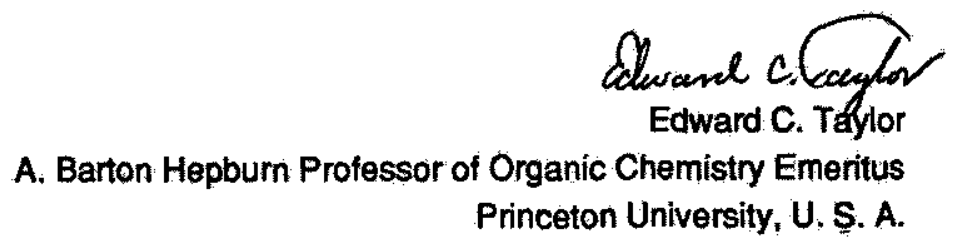

Princeton University, U. S. A. 